\title{
Optimizing the Aesthetic Outcome of Short Scar Periareolar Inferior Pedicle Reduction Mammaplasty
}

\author{
NIVEEN FATHY AL-MAHMOUDY, M.D. and KHALED A. REYAD, M.D. \\ The Department of Plastic Surgery, Faculty of Medicine, Ain Shams University, Egypt
}

\begin{abstract}
Background: The inferior pedicle is still the most common pedicle used for breast reduction using both inverted $\mathrm{T}$ and vertical closure, however many unfavorable results may follow as bottoming out and decreased upper pole fullness. Many techniques were done to overcome the drawbacks of the inferior pedicle technique.
\end{abstract}

Patients and Methods: 10 patients complain of huge ptotic breast had inferior pedicle technique with full release of pedicle from skin with glandular brassiere support in form of lower pillars on both sides with vertical skin closure.

Results: Satisfactory long term results both objectively and subjectively, with good upper pole fullness and without bottoming out and only with vertical scar.

Conclusion: This technique combined both the merits of the inferior pedicle reliability and better aesthetic results.

Key Words: Inferior pedicle - Short scar-Breast reduction.

\section{INTRODUCTION}

Breast reduction of huge breasts presents one of the greatest encounters to aesthetic surgeons. The main aim of breast reduction is to reduce the volume of the breasts, to place the breast mound and nipple in an anatomical position, with a firm and non-ptotic more youthful appearance with improved projection.

Several techniques have been suggested in order to advance breast contour, obtain symmetry and minimizing the presence of scars. Although the regular "inverted T" is still quite generally used, the horizontal/sub-mammary scar remains a main concern, especially in younger patients [1]. In a successive practice, new ideas performed since 1980s, directing mainly on gaining a surgical technique to lessen the horizontal scar as possible. Thus, new designs have appeared as the L scar $[2,3]$, inverted $\mathrm{T}$ scar with a minimum horizontal component [4], peri-areolar scar [5,6] and the vertical scar [7]. Recently, vertical scar reduction mammaplasty has developed more popularity due to less scarring.
The inferior pedicle with inverted $\mathrm{T}$ scar reduction Mammaplasty, one of the most regularly performed technique [8], was first introduced by Riberio [9] followed by many modifications. These include the use of synthetic mesh [10,11] suspending the pedicle $[\mathbf{1 2 , 1 3}$ and a superficial fascial system suspension [14] thus becoming less reliant upon the skin brassiere. These modifications aimed to a long-term lift of the breast. Hammond proposed a modification in skin closure to eliminate sub mammary scar [15].

Our technique proposes a modification for a short scar periareolar inferior pedicle breast reduction technique. That includes a separation of the dermal inferior pedicle from the skin of the lower incision, suspension of the breast parenchyma using caudal pillars from both sides with vertical skin closure.

\section{PATIENTS AND METHODS}

This study was done in Ain Shams University Hospitals during the period from January 2017 to March 2018. 10 patients with huge ptotic breast were included after obtaining formal consent from the patients and explaining the possible complications and undesirable effects post-operatively. Obtaining approval from board faculty in our institute was done before any surgery. This was a prospective, randomized study seeking an improvement of breast shape and size. Full medical history was recorded. Pre-operative examination and investigations revealed no suspicion of any malignancy in the breast. All patients were fit for surgery. Standard photographs were obtained.

\section{Surgical technique:}

The patients were marked pre-operatively in a standing position. The chest mid-line was marked from the sternal notch to the umbilicus, and distances between the mid clavicular point and nipples were measured and documented. Breast meridians were marked bilaterally. The infra mammary fold 
was marked and projected over the breast. The upper border of the areola was marked $4 \mathrm{~cm}$ above the intersection between the projected inframammary fold and breast meridians on both sides (guided by the main bulk of the breast) [15]. The distance between the neo-nipple and sternal notch was recorded. The distance from the inframammary to the old nipple was recorded. The pedicle with $8-10 \mathrm{~cm}$ base width was centered over breast meridian containing the nipple areola complex. The skin was marked as donut skin pattern with the lower end marked $2-4 \mathrm{~cm}$ above the original infra-mammary fold. The extent of medial and lateral skin excisions were marked in respect to the meridian of both breasts and relevant excess amounts to be excised, by rotating the breast to either side upward respectively. Medial and lateral pillars were determined as $6-8 \mathrm{~cm}$, starting from the end of areolar opening Fig. (1).

The operation was done under general anesthesia, where the patient was lying in semi-setting position with both arms extended, after sterilization and draping, tumescent adrenaline-saline solution was infiltrated in the areas to be excised, then deepithelization of the pedicle was done Fig. (2), starting inferiorly $2-4 \mathrm{~cm}$ above the infra-mammary line. Excision of the excess breast tissue above and on both sides of the pedicle was completed Fig. (3), preserving $2 \mathrm{~cm}$ thickness of a predesigned medial and lateral pillars.

Separation of the dermal inferior pedicle from the skin of the lower incision is then deepened slanting downward away from the pedicle to separate it from the intact skin below toward the infra-mammary fold to preserve as many feeding vessels as possible, with caution to maintain the chest wall attachment of the pedicle to ensure the entrance of adequate blood supply and its venous drainage Fig. (4).

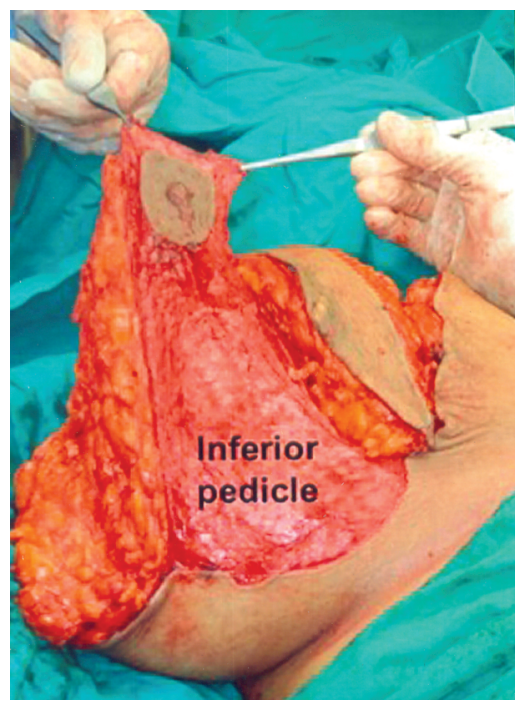

Fig. (2): (LT) de-epithelialization of the pedicle till $4 \mathrm{~cm}$ above the infra-mammary fold.
The breast was dissected till the level of the second rib to accommodate the pedicle Fig. (5). The next step was in-setting of the pedicle, with placing the nipple areola complex in its new position. The medial and lateral pillars were sutured to each other and fixed to the breast tissue caudal to the pedicle to enhance support of the breast with control of the breast base width through the depth of sutures and their tightening (Fig 6).

The glandular tissues caudal to the pillars and on both sides of the pedicle were completely excised preserving the skin above to allow vertical closure. Shortening of the lower part of the vertical line through tightening of the dermal sutures and thinning of the skin with complete excision of breast tissue caudal to the $8 \mathrm{~cm}$ pillars on both sides was done Fig. (7).

Hemostasis and drains were applied. Closure in layers was done \& finally dressing was applied. Suction drains were removed after 3 days. Dressings were done till complete healing of the wounds.

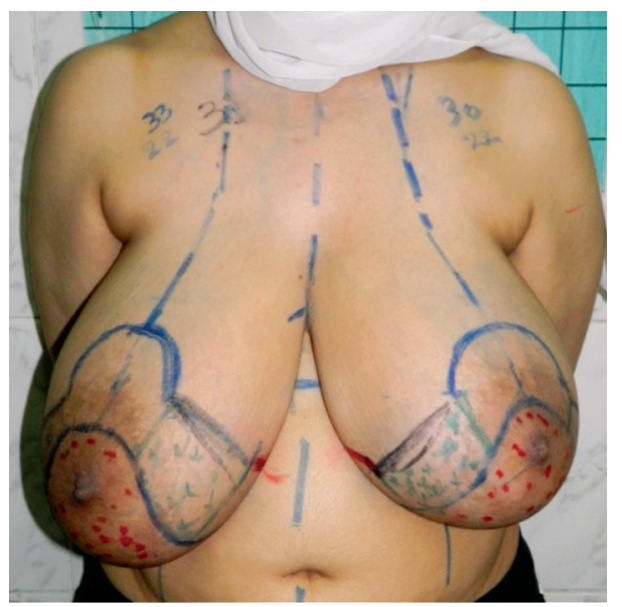

Fig. (1): Pre-operative marking of 32 years old female with bilateral huge breasts.

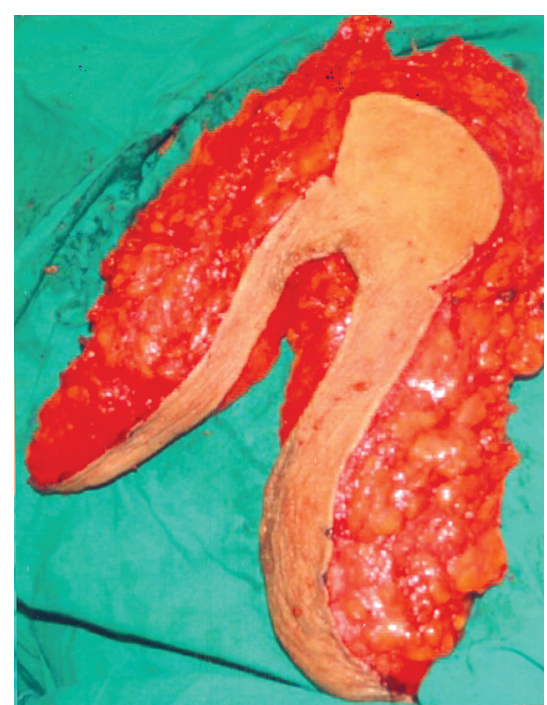

Fig. (3): (RT) excised skin and breast tissue. 

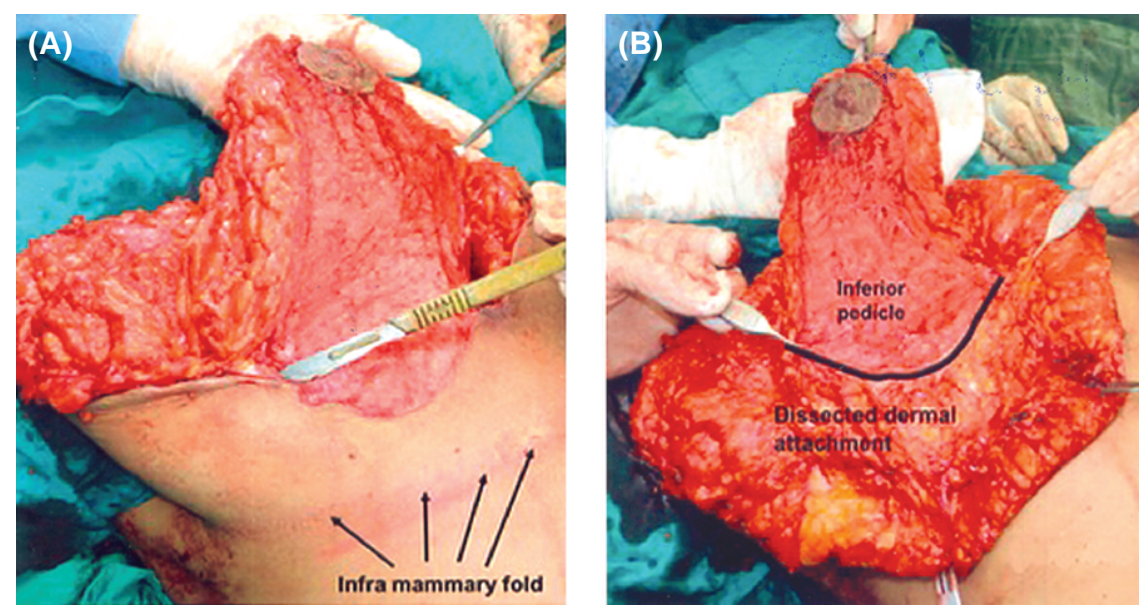

Fig. (4): (A, B) Separation of the dermal inferior pedicle from the skin of the lower incision.

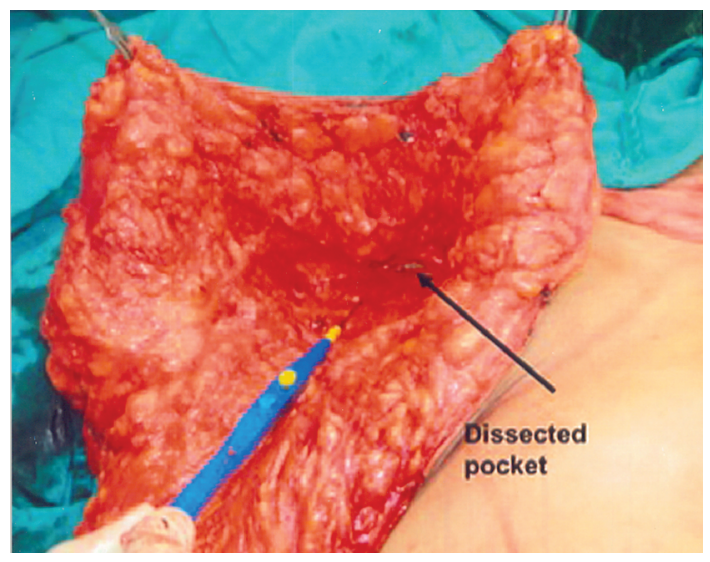

Fig. (5): Dissection of superior pocket to accommodate the inferior pedicle.

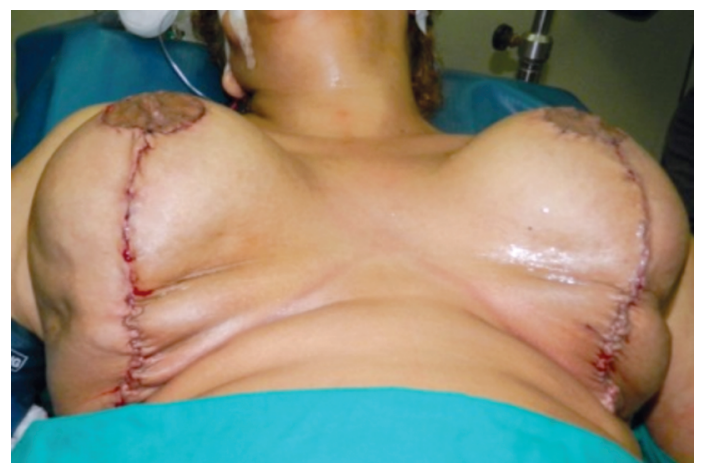

Fig. (7): Vertical line closure.

\section{RESULTS}

Ten female patients were included, age was ranging from 25-55 years (Table 1), the average time of surgery was ranging between 2-3 hours, none of the patients recieved blood transfusion either intraoperative or in the post-operative period. The mean time for discharging the patients was 2 days (range: 1-4), none of the patients had NAC complications (nipple areola congestion, necrosis or sloughing). There was no hematoma, nor seroma. However, minor complications as mild wound

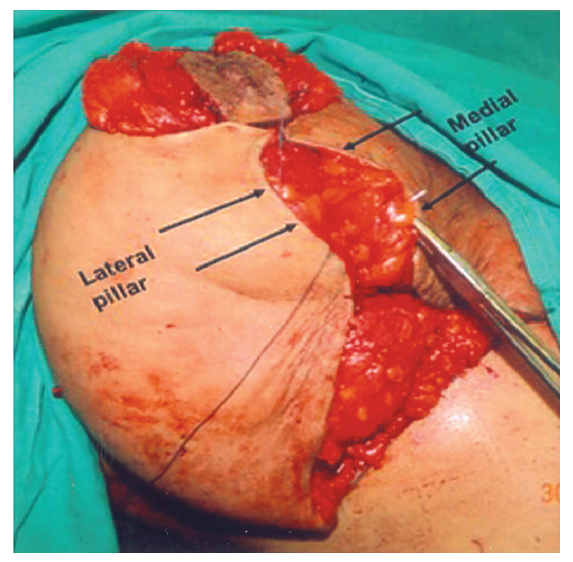

Fig. (6): Closure of the medial and lateral pillars.

infection with disrupted sutures in the lower part of the vertical line in 2 patients which was managed conservatively.

All patients were followed-up to one year and evaluation was done by Strasser's cosmetic satisfaction score [16]. All of the point added together to get a total score where an excellent result gets a 0 score, score of 1-4 are good results, 5-14 are medicore, 15 or more are poor (Table 2) Figs. $(8-10)$.

Table (1): Demographic data of patients.

\begin{tabular}{|c|c|c|c|c|c|c|c|}
\hline \multirow{2}{*}{ No. } & \multirow{2}{*}{ Age } & \multicolumn{2}{|c|}{$\begin{array}{l}\text { Pre-operative } \\
\text { measurement }\end{array}$} & \multirow{2}{*}{$\begin{array}{c}\text { New } \\
\text { nipple } \\
\text { distance }\end{array}$} & \multicolumn{2}{|c|}{$\begin{array}{c}6 \text { months } \\
\text { post-operative } \\
\text { measurement }\end{array}$} & \multirow{2}{*}{ Complication } \\
\hline & & $\begin{array}{l}\text { SSN- } \\
\text { NAC }\end{array}$ & $\begin{array}{l}\text { NAC- } \\
\text { IFM }\end{array}$ & & $\begin{array}{l}\text { SSN- } \\
\text { NAC }\end{array}$ & $\begin{array}{l}\text { NAC- } \\
\text { IFM }\end{array}$ & \\
\hline 1 & 32 & 31 & 18 & 22 & 23 & 14 & \\
\hline 2 & 34 & 32 & 22 & 21 & 22 & 16 & \\
\hline 3 & 27 & 30 & 17 & 22 & 22 & 14 & \\
\hline 4 & 41 & 32 & 22 & 21 & 22 & 15 & \\
\hline 5 & 44 & 38 & 26 & 23 & 24 & 16 & \\
\hline 6 & 45 & 39 & 26 & 22 & 24 & 16 & \\
\hline 7 & 33 & 32 & 23 & 21 & 21 & 17 & Disrupted suture \\
\hline 8 & 38 & 33 & 20 & 20 & 22 & 14 & \\
\hline 9 & 42 & 40 & 26 & 23 & 24 & 16 & Disrupted suture \\
\hline 10 & 34 & 36 & 21 & 22 & 23 & 14 & \\
\hline
\end{tabular}


Table (2): Strasser's grading system for satisfaction score.

\begin{tabular}{lccccccc}
\hline \multicolumn{7}{c}{ Strasser's grading system for cosmetic procedures } \\
\hline No. & Mal-position & Distortion & Assymetry & Contour deformity & Scar & Over all & Plan \\
\hline 1 & 1 & 0 & 1 & 0 & 0 & 2 & Nothing \\
2 & 1 & 0 & 0 & 0 & 1 & 2 & Nothing \\
3 & 0 & 0 & 2 & 0 & 1 & 3 & Nothing \\
4 & 0 & 1 & 0 & 0 & 0 & 1 & Nothing \\
5 & 0 & 1 & 2 & 0 & 1 & 3 & Nothing \\
6 & 2 & 0 & 0 & 0 & 0 & 2 & Nothing \\
7 & 1 & 1 & 0 & 1 & 1 & 4 & Nothing \\
8 & 0 & 0 & 1 & 0 & 0 & 1 & Nothing \\
\hline
\end{tabular}

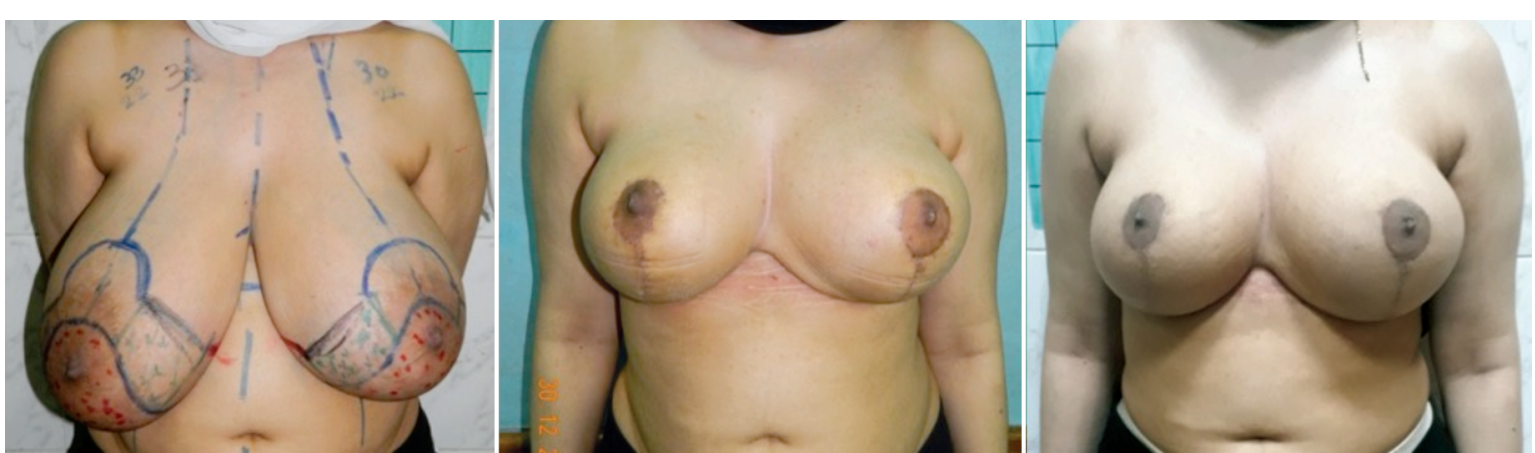

Fig. (8): A pre-operative front view (left), immediate post-operative front view (middle) and 8 months post-operative front view (right).

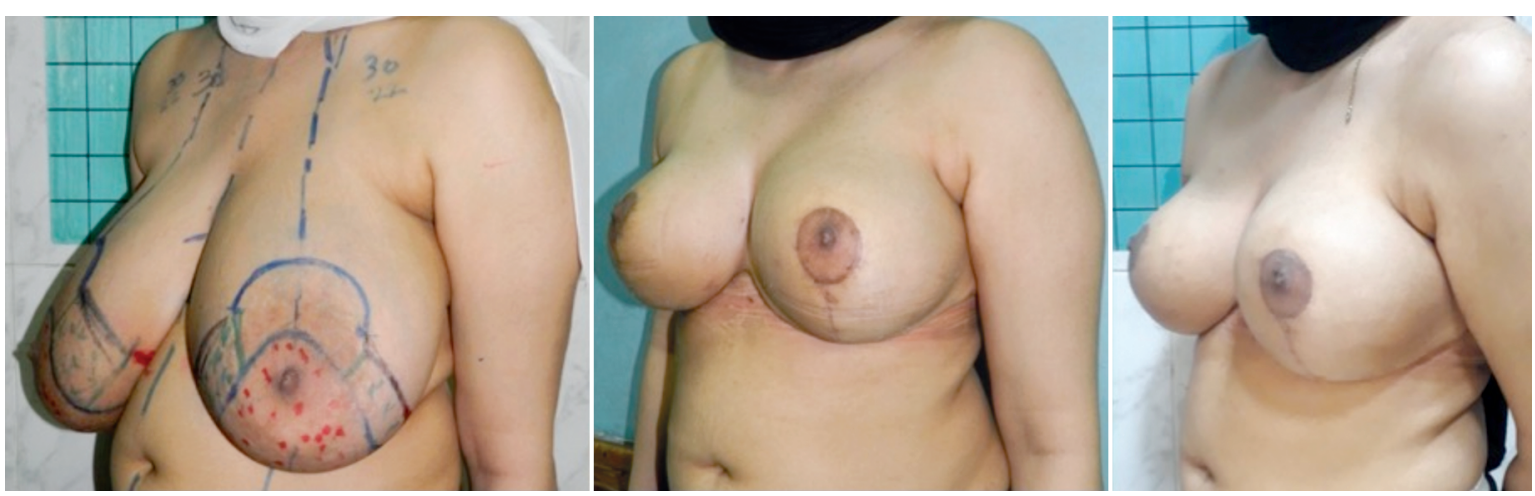

Fig. (9): A pre-operative left oblique view (left), immediate post-operative oblique view (middle) and 8 months postoperative left oblique view (right).
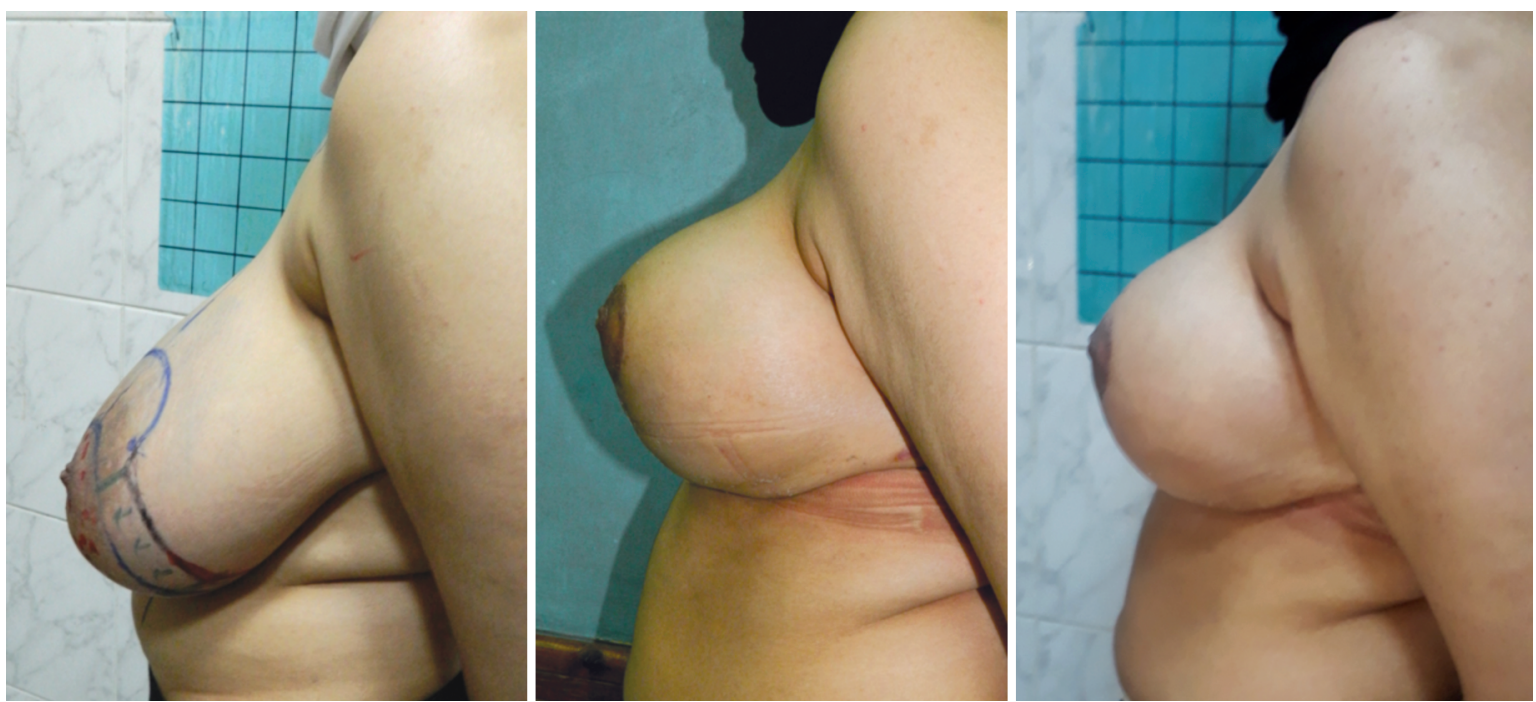

Fig. (10): A pre-operative front lateral view (left), immediate post-operative lateral view (middle) and 8 months postoperative lateral view (right). 


\section{DISCUSSION}

Development in breast reduction techniques arose in the twentieth century with different modifications in the pedicles and skin closure. Numerous techniques were described in terms of refining breast shape results while looking for to diminish visible scars, however, the size and quality of scars endure a main concern in the breast [17].

1n 1999, Hammond [15] proposed the short scar periareolar breast reduction where inferior pedicle was used with vertical closure to minimize one of the major drawbacks of inferior pedicle technique. In this study, a modification to was done in the form of complete separation of dermal attachment of inferior pedicle from the skin of lower incision to allow maximal mobility without jeopardizing the blood supply to NAC and without separation of the scarpa's fascia attachments to the inframammary fold.

The main sources of blood supply to the breast are the internal mammary, lateral thoracic, and anterior intercostal arteries. The inferior pedicle is a glandular pedicle receiving its nourishment from the deep surface of the gland through the lower anterior intercostal perforators [18], which could be detected piercing the pectoralis major muscle and apparently heading towards the NAC guided by a bilaminar vertical septum [19]. The superficial venous system of the lower pole of the breast courses inferiorly in the mid mammary line toward the infra mammary fold draining to the $4^{\text {th }}$ and/or $5^{\text {th }}$ intercostal spaces, but some of them may run more downward to blend with the superficial veins of the abdomen [20]. Preservation of $1-2 \mathrm{~cm}$ of circumareolar dermis is recommended in the inferior glandular pedicle in order not to compromise the local circulatory pathways around the areolar margin. Apart from inferior and central glandular pedicles, a dermal connection should be maintained to preserve the superficial venous drainage [21].

In the current study, separation of the dermal inferior pedicle from the skin of the lower incision was done and deepened slanting downward away from the pedicle to separate it from the intact skin below toward the infra-mammary fold, to allow maximum mobility, shaping and advancement of the pedicle without affection of vascular input or venous drainage of the breast owing to deeper sources. In a previous study [22], the same concept of separation of dermal attachment of pedicle was performed with no vascular complication to NAC.
To deal with this inferior pole sagging, suspension of the pedicles to the chest wall have been suggested $[\mathbf{2 3 , 2 4 ]}$ allowing for better long-term results $[25,26]$. Other uses the dermal suspension sling [23]. Moreover, other authors resorted to internal suspension with a mesh or allogeneic materials to build an internal brassiere or sling $[27,28]$. Although this method appears to elude the inferior migration of breast parenchyma, there is still a possible danger of infection or tissue reaction.

In this study, pillars were created lateral and medial to the excised part starting from the ends of the areolar opening, when approximated in the mid mammary line they act as suspension hammock for the upward displaced inferior pedicle that offers glandular support, better projection, with no bottoming out and better conical shape of the breast. Moreover, it increased the medial pole fullness of the breast with good long-term results. Evaluation was done using Strassers' cosmetic score, showed that results were ranged one to four, which were good results.

\section{Conclusion:}

This technique combined both the merits of the inferior pedicle reliability, with better aesthetic results (a unique vertical scar, maintenance of results over time, and no "bottoming out" deformity), due to glandular brassiere used instead of the regular skin brassiere.

\section{REFERENCES}

1- Modified Vertical Reduction Mammaplasty: Ten years of experience: Augusta Cardoso \& João Martins \& Gustavo Coelho \& Rui Barbosa \& Horácio Costa, Received: 14 July 2013/Accepted: 31 December 2013/Published online: 15 February 2014 Eur. J. Plast. Surg., 37: 215-26, 2014.

2- Bozola A.R.: Breast reduction with short L scar. Plast. Reconstr. Surg., 85 (5): 728-38, 1990.

3- Ribeiro L. and Backer E.: Mastoplastia com pediculo de seguridad. Rev. Esp. Cir. Plast., 16: 223, 1973.

4- Marchac D. and De Olarte G.: Reduction mammoplasty and correction of ptosis with a short inframammary scar. Plast. Reconstr. Surg., 69: 45, 1982.

5- De Benito J. and Sanza I.F.: Periareolar techniques for mammary reduction and elevation. Aesthetic Plast. Surg., 17: 97-100, 1993.

6- Becker H.: Subareolar mastopexy: Update. Aesthet. Surg. J., 23 (5): 357-62, Saint Louis, 2003.

7- Orlando J.C.: The superomedial dermal pedicle for nipple transposition. Br. J. Plast. Surg., 28: 42-5, 1975.

8- Zic R., Vlajcic Z., Dewing D., et al.: The "dermal cage": A modification of the inferior pedicle breast reduction. Aesthetic Plast. Surg., 37: 364-71, 2013. 
9- Ribeiro L.: A new technique for reduction mammaplasty. Plast. Reconstr. Surg., 55: 330-4, 1975.

10- Johnson G.W.: Central core reduction mammoplasties and Marlex suspension of the breast tissue. Aesthet. Plast. Surg., 5: 77-84, 1981.

11- Goés J.C., Landecker A., Lyra E.C., Goés R.S. and Godoy P.M.: The application of mesh support in periareolar breast surgery: Clinical and mammographic evaluation. Aesthet. Plast. Surg., 28: 268-74, 2004.

12- Hinderer U.T.: Mammaplasty: The dermal brassiere technique. Aesthet. Plast. Surg., 2: 1-20, 1978.

13- Alvo Z.: Mammaplasty for mild and/or ptotic breast through short incision at the inframammary sulcus: A personal approach. Aesthet. Plast. Surg., 21: 352-5, 1997.

14- Lockwood T.: Reduction mammaplasty and mastopexy with superficial fascial system suspension. Ann. Plast. Surg., 103: 1411-20, 1999.

15- Hammond D.C.: Short scar periareolar inferior pedicle reduction (SPAIR) mammaplasty. Plast. Reconstr. Surg., 103: 890-901, 1999.

16- Strasser E.: An objective grading system for the evaluation of Cosmetic Surgical Result Plast. Reconstr. Surg., 104 (7): 2282-5, 1999.

17- Thorne C.H., Bartlett S.P., Beasley R.W., Aston S.J. and Gurtner G.C.: Grabb and Smith's plastic surgery, $6^{\text {th }}$ edn, Lippincott Williams \& Wilkins, 2007.

18- Nakajima H., Imanishi N. and Aiso S.: Arterial anatomy of the nipple-areola complex. Plast. Reconstr. Surg., 96: 843-5, 1995.

19- Awad M., Magdi M., Sadek E.Y., Helal H. and Abdel Hamid W.A.: New Septum in the Female Breast Arch. Plast. Surg., 44: 101-8, 2017.
20- Corduff N., Rozen W.M. and Taylor G.I.: The superfic ialvenous drainage of the breast: A clinical study and implications for breast reduction surgery, J. Plast. Reconstr. Aesthet. Surg., 63: 809-13, 2010.

21- Climo M.S. and Alexander J.E.: Intercostal circulation: Nipple survival in reduction mammaplasty in the absence of a dermal pedicle. Ann. Plast. Surg., 4: 128-32, 1980.

22- Elmelegy N.G., Sadaka M.S., Hegazy A.M. and Abdeldaim D.E.: Treatment of Gigantomastia using a medial-lateral bipedicle reduction mammoplasty: The role of Dopplerassisted pre-operative perforator identification Aesth. Plast. Surg., 42: 73-9, 2018.

23- The Dermal Suspension Sling: Shaping the Inferior Pedicle during Breast Reduction: Anthony Echo - Gerardo Guerra - Eser Yuksel, Aesth. Plast. Surg., 35: 608-16, 2011.

24- Aydin H., Tumerdem B., Onel D. and Cerci-Ozkan A.: Reduction mammaplasty using inferior pedicle technique combined with dermal suspension. Plast. Reconstr. Surg., 111: $1362-3,2003$

25- Baumeister R.G.: Curtain type combined pedicle reduction mammoplasty with internal suspension for extensive hypertrophic and ptotic breasts. Br. J. Plast. Surg., 56: 114-9, 2003.

26- Perez-Macias J.M.: Personal mastopexy technique for breast stabilization: Update. Br. J. Plast. Surg., 57 (2): 178,2004

27- Johnson G.W.: Central core reduction mammoplasties and Marlex suspension of the breast tissue. Aesthet. Plast. Surg., 5: 77-84, 1981.

28- Goés J.C., Landecker A., Lyra E.C., Goés R.S. and Godoy P.M.: The application of mesh support in periareolar breast surgery: Clinical and mammographic evaluation. Aesthet. Plast. Surg., 28: 268-74, 2004. 